
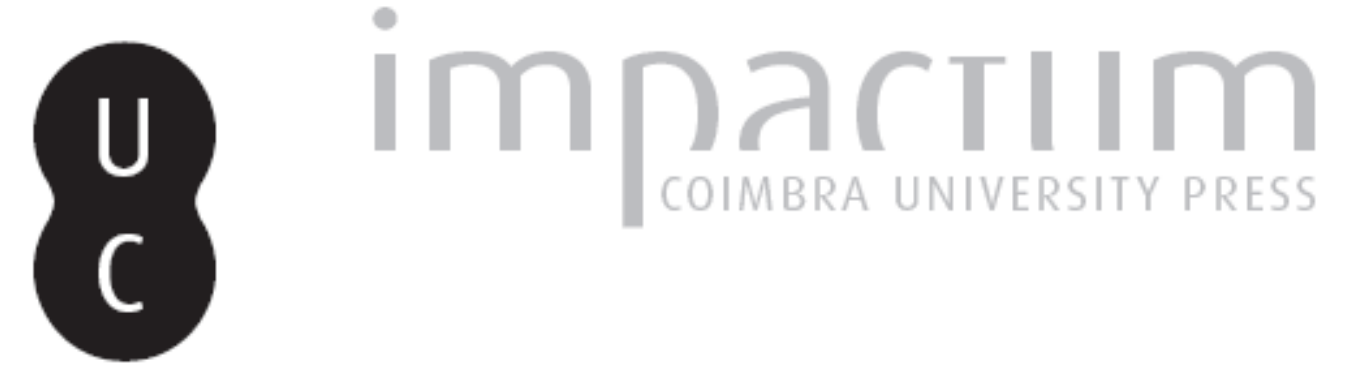

\title{
[Recensão a] CATROGA, Fernando - Os Passos do homem como restolho do tempo. Memória e fim do fim da história
}
Autor(es):
Borges, Anselmo

Publicado por: Imprensa da Universidade de Coimbra

URL

persistente:

URI:http://hdl.handle.net/10316.2/36551

DOI:

DOI:http://dx.doi.org/10.14195/1647-8622_9_19

Accessed : $\quad$ 26-Apr-2023 12:41:29

A navegação consulta e descarregamento dos títulos inseridos nas Bibliotecas Digitais UC Digitalis, UC Pombalina e UC Impactum, pressupõem a aceitação plena e sem reservas dos Termos e Condições de Uso destas Bibliotecas Digitais, disponíveis em https://digitalis.uc.pt/pt-pt/termos.

Conforme exposto nos referidos Termos e Condições de Uso, o descarregamento de títulos de acesso restrito requer uma licença válida de autorização devendo o utilizador aceder ao(s) documento(s) a partir de um endereço de IP da instituição detentora da supramencionada licença.

Ao utilizador é apenas permitido o descarregamento para uso pessoal, pelo que o emprego do(s) título(s) descarregado(s) para outro fim, designadamente comercial, carece de autorização do respetivo autor ou editor da obra.

Na medida em que todas as obras da UC Digitalis se encontram protegidas pelo Código do Direito de Autor e Direitos Conexos e demais legislação aplicável, toda a cópia, parcial ou total, deste documento, nos casos em que é legalmente admitida, deverá conter ou fazer-se acompanhar por este aviso.

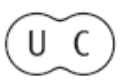




\section{hipóteses de século}

ESTUD OSD O SÉCULO

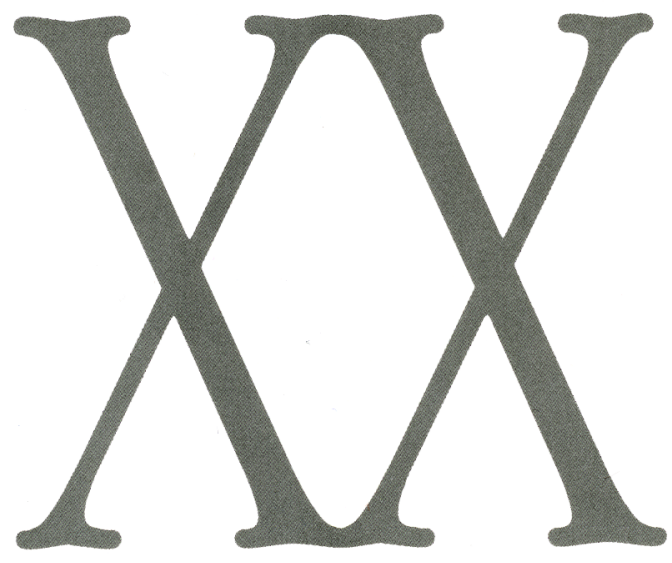

número $9 \cdot 2009$

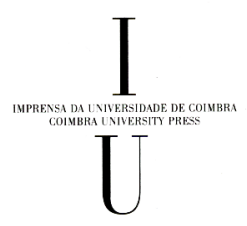


CATrogA, Fernando - Os Passos do homem como restolho do tempo. Memória e fim do fim da história. Coimbra: Almedina, 2009.310 p. ISBN 9789724038575.

Este texto tem a sua origem numa exposiçáo oral - constatar-se-á que mantém muito de oralidade - de apresentação da obra Os Passos do Homem como Restolho do Tempo. Memória e Fim do Fim da História, do Doutor Fernando Catroga, Professor Catedrático da Faculdade de Letras da Universidade de Coimbra. Quer, como a exposiçáo e associando-se ao Doutor Fernando Catroga, ser uma homenagem à memória do amigo comum, Miguel Baptista Pereira.

1. Antes de mais, agradeço o convite generoso que me foi feito para esta apresentaçáo, que tanto me honra. Seguindo o preceito de Plínio - ne sutor ultra crepidam -, procurarei náo ir além da sandália. De facto, a melhor apresentaçáo da obra é ela mesma na excelência de obra de maturidade de um prestigiado pensador, investigador $\mathrm{e}$ professor, de renome internacional.

Fernando Catroga é conhecido e reconhecido pelas suas investigaçöes sobre a morte. Também escreveu a melhor obra em língua portuguesa sobre a problemática da secularização, laicidade e religiâo civil: Entre Deuses e Césares. Ele é o historiador que entre nós melhor faz o cruzamento da história e da filosofia.

Tenho de confessar o imenso prazer intelectual na leitura desta obra: o pensamento é profundo, as referências sáo sem limite, a bibliografia é extensa, há sugestōes em desafio constante que nos convocam para o diálogo crítico. Repito: obra de excelência da maturidade intelectual, muito exigente na sua profundidade reflexiva. A sua melhor introduçáo foi escrita pelo autor nas Palavras Prévias, de belo recorte literário.
Tem três momentos, ou, melhor, eixos fundamentais: a história como superaçáo da morte; a episteme da história; as filosofias da história, o fim da história e o fim do fim da história.

2. Entramos no primeiro momento. Porque vamos à história, porque escrevemos história? Porque há a questão, o enigma, o mistério do tempo e da morte e mortalidade. Se soubéssemos o que é o tempo, teríamos resolvido o nosso enigma. Heródoto escreveu as suas Histórits "para que os feitos dos homens se náo desvaneçam com o tempo nem fiquem sem renome os grandes empreendimentos realizados pelos Helenos e pelos Bárbaros».

Então, fundamentalmente queremos saber o que e quem somos. Na história, há um interesse essencial antropológico. Porque a nossa identidade é narrativa. Quando perguntamos a alguém quem é, narra-nos a sua história, a sua biografia. Mas, para narrá-la completamente, terá de passar à sua família, pais, avós, bisavós..., ao país, ao continente em que está inserido, à história toda da Humanidade, à história da vida, da passagem do australopithecus ao sapiens sapiens e demens demens, à história toda do cosmos até ao big bang e, aí chegado, perguntar ainda: porque há algo e náo nada, porquê o big bang?...

Isto mostra que náo há lugar para a separaçáo entre as ciências da natureza, baseadas na explicaçáo (erklären), e ciências do espírito, baseadas na compreensáo (verstehen). Afinal, sáo todas hermenêuticas. Por outro lado, vemos que o nosso passado sáo as nossas costas, que nunca vimos, e o nosso rosto, que também não vemos, somos nós voltados para os outros e para o futuro. $E$, se perdêssemos a memória, não perderíamos apenas o passado, mas a própria identidade. $O$ esquecimento é a morte. 
Assim, quando se pensa no enigma do tempo, é-se confrontado com a sua concepçáo circular - o círculo era para os gregos a melhor representaçáo da eternidade -, a concepçáo sobretudo moderna, linear... Santo Agostinho ia dizendo que, se náo lhe perguntassem, sabia o que é o tempo, mas, se lhe perguntassem e tivesse de responder, náo sabia, porque o passado já não existe, o futuro ainda năo existe e o presente nunca o agarramos, pois é passagem. Ou está como presente presente, e o passado como presente na memória e o futuro como presente na expectativa?

Mas, se reflectirmos de forma conveniente e adequada, observaremos que o tempo e a história náo podem entender-se de modo exclusivamente linear, isto é, de modo unidimensional, como se as diferenças e relaçóes entre o passado, o presente e o futuro pudessem reduzir-se à simples relaçáo do antes e depois. O tempo é linear e entrecruzado, numa rede de relaçóes múltiplas e complexas, como reflecte Fernando Catroga, na esteira de Miguel Baptista Pereira e Jürgen Moltmann.

Há certamente presente, passado e futuro. Mas cada modo do tempo tem ele próprio tríplice modo. Isto é: o passado não pode entender-se pura e simplesmente como o ultrapassado e superado; ele próprio teve um passado, um presente e um futuro.

Trata-se de um presente passado, com o seu próprio passado e também o seu futuro.

De modo semelhante, o nosso presente enquanto presente actual tem em si o passado presente e o futuro presente. Não pressupóe o presente actual o futuro do presente passado? Por outras palavras, náo nasceu o nosso presente das esperanças, projectos e possibilidades do presente passado?

E o mesmo deverá dizer-se do futuro, que, no seu presente, enquanto concretizaçáo do nosso futuro presente, estará entrelaçado com o seu passado, que é o nosso presente actual, e com o seu próprio futuro.

Portanto, o passado nảo é pura e simplesmente o passado e superado; o passado vive e actua no presente. $O$ passado tinha e tem futuro. Há futuro no passado. $\mathrm{O}$ passado também sonhou, nele fermentavam possibilidades, também esteve grávido de projectos e de esperanças. Esse futuro do presente passado tem a sua concretização no nosso presente, mas o nosso presente actual enquanto realizaçáo desse passado é apenas uma das suas concretizaçóes. Apenas uma. Tanto assim é que, de vez em quando há renascimentos. E há renascimentos porquê? Porque houve um passado com imensas esperanças, enormes sonhos e possibilidades, com projectos maiores do que aqueles que encontraram realizaçáo. Houve, portanto, projectos, esperanças e possibilidades do passado que foram esquecidos e até reprimidos e, por isso, há movimentos que vão ao passado para recuperar as esperanças e os projectos que ficaram ocultos, que foram esquecidos e reprimidos, para de novo os colocar em marcha. As esperanças reprimidas sáo reactivadas no projecto do futuro - náo é aqui que se coloca, Doutor Fernando Catroga, toda a sua longa meditação sobre a memória e o monumento?

Mas também o futuro do nosso presente há-de ficar sempre aquém daquilo que o presente sonhou. Quer dizer, o presente futuro, que será também realidade resultante do nosso futuro presente, náo esgotará as nossas possibilidades e sobretudo a nossa esperanças. Como o presente actual se náo identifica com o futuro do presente passado, também o presente futuro se não adequará ao futuro do presente. $\mathrm{E}$ o mesmo é necessário dizer do próprio futuro, também ele sempre com futuro.

Aqui está, pois, a história como memória contra o esquecimento, contra a morte e a perda de identidade. 
3. O segundo eixo tem a ver com a episteme da história. Pode a história pretender constituir-se em ciência? Aristóteles negava essa pretensáo, pois a ciência refere-se ao universal. Ora, a história tem como objecto o singular, irrepetível e contingente. A contingência e $o$ acaso em história sáo algo que náo deixa de impressionar profundamente, na medida em que estamos em presença de acontecimentos imprevisíveis e contingentes que acabam por ter uma incidência histórica aparentemente indevida. Pascal disse-o de forma pregnante: o nariz de Cleópatra, se náo fosse como era, a história do mundo seria diferente. E, realmente, se Marco António náo tivesse ido no encalço de Cleópatra, poderia ter vencido e a história mundial seria outra. $\mathrm{O}$ príncipe russo náo se converteu ao isláo, e, com ele, o povo russo, porque o islāo náo permite bebidas alcoólicas... Se a Rússia fosse islâmica e não cristā, como seria a história do mundo?

Assim, quanto a essa pretensão científica da história erguem-se algumas objecçóes, temíveis.

Em primeiro lugar, o historiador não observa directamente os factos. Pela sua própria natureza, a história é conhecimento do passado. Mas o passado já náo existe. $\mathrm{O}$ historiador e filósofo R. Wittram na sua obra Das Interesse an der Geschichte, escreveu: «A mim os grandes acontecimentos históricos do passado afiguram-se-me como cataratas geladas, imagens congeladas pelo gelo da vida que se foi e nos mantém à distância. Gelamos à vista dos grandes feitos: reinos caídos, culturas destruídas, paixóes apagadas, cérebros mortos. Se tomamos isto a sério, podemos sentir que nós, historiadores, temos uma ocupação bem estranha: habitamos na cidade dos mortos, abraçamos as sombras, recenseamos os defuntos».

Depois, o conhecimento do passado só é possível indirectamente, e permanece subjectivo. Náo vai o historiador para o seu ofício com a sua subjectividade - homem de uma época, de uma classe, de um país, com determinados interesses? Projectará inevitavelmente sobre o passado os seus valores próprios, os seus interesses e preocupaçōes presentes...

Em terceiro lugar, náo sendo possível a experimentação nem a repetibilidade, pois se trata de acontecimentos únicos e irrepetíveis, nāo poderá estabelecer leis...

Fernando Catroga é bem consciente destas objecçóes. Por isso, opóe-se à história objectivista, positivista e não pensa que a história seja mestra da vida... Aliás, como escreveu Paul Valéry, «a história justifica o que se quiser. Ela náo ensina rigorosamente nada, pois contém tudo e dá exemplos de tudo».

Mas é possível reconstruir o facto histórico, porque há vestígios, sinais, traços - aqui está o título da obra: Os Passos do Homem como Restolho do Tempo. O historiador representa, então, re-presentifica o passado, sempre na convergência da explicação e da compreensāo e tendo em conta a imaginaçāo, que nảo fantasia, para perceber os outros possíveis e assim fazer uma síntese. Tem, pois, de precaver-se contra o perigo de, já que escreve a história do fim para o princípio, julgar que há uma necessidade histórica, como se o passado só pudesse ser o que foi.

Dada a sua subjectividade inevitável e sempre histórica, impóe-se distinguir entre a factualidade e a significação da história. Esta distinção faz entender a necessidade de reescrever permanentemente a história. Também por causa da interpenetraçáo dos tempos ou do seu cruzamento, de que falámos. E ainda porque há a Wirkungsgeschichte (a história efeitual), de que falava Gadamer... Precisamente por isso, náo é só a história vivida que é nova, também o é a historiografia: a história está sempre a ser reescrita. 
4. O terceiro eixo diz respeito ao fim do fim da história.

Aqui, temos todo o campo da teologia da história e da sua secularizaçăo em filosofias da história, segundo o esquema sucessivo de teodiceia, logodiceia, historiodiceia, agregando a mercadodiceia.

Para a intelecçáo desta problemática, é decisiva a passagem pela conceito de secularizaçáo, nos seus vários sentidos: a secularização da consciência, que deriva do esbatimento da relação pessoal com a Transcendência divina; a secularizaçáo enquanto autonomia das realidades terrestres, que constitui uma conquista civilizacional fundamental, sobretudo na sua incidência sócio-política - separaçáo da(s) Igreja(s) e do Estado, da religião c da política; e a secularizaçáo enquanto traz para a imanência da história, herdando-os, conteúdos semânticos da escatologia cristá, referentes à meta-história - pense-se, por exemplo, nos conceitos de salvaçáo e de Reino de Deus, realizados numa sociedade humana finalmente transparente, sem contradiçáo nem exploraçáo.

Se a história é uma herança essencialmente bíblica - ao conceito grego de geração, que implica necessidade, contrapóe-se o conceito bíblico de criaçăo, que implica liberdade --, na perspectiva cristã, a história tem o seu fim, enquanto termo e telos na meta-história.

Foi quando a história se acelerou, concretamente com a revoluçáo da ciência e da técnica, que, bebendo, por exemplo, em Joaquim de Fiori com a sua interpretação da Santíssima Trindade e a tripartiçáo da história em reino ou idade do Pai, idade do Filho e idade do Espírito Santo, se elaborou a lei dos três estádios da história e a partir da ideia de criaçáo pelo Logos se procurou a racionalidade da história $\mathrm{esc}$ avançou pela secularizaçăo no terceiro sentido indicado.
$\hat{E}$ aqui que se inserem nomeadamente Hegel e o marxismo. Segundo Hegel, a história do mundo é o tribunal do mundo (Weltgeschichte Weltgericht), a teodiceia converte-se em historiodiceia, pois a história é racional enquanto desenvolvimento dialéctico de Deus. O marxismo náo é compreensível sem o seu horizonte bíblicoproférico-messiânico. Também Ernst Bloch elaborou toda a sua filosofia à volta da esperança do Reino de Deus sem Deus humanizaçáo da natureza e naturalizaçăo do homem -, no quadro de uma salto sobrenatural da própria natureza...

Mas a consumaçáo da história na sua imanência é contraditória, porque a história, pela sua natureza, é sempre finita $\mathrm{e}$ contingente. $E$, por outro lado, há constitutivamente o novo ineliminável...

Aqui, sem pretender meter-me em debates intermináveis, gostaria apenas de acenar para a ideia de que a modernidade ainda é teológica, no sentido de que herda e quer realizar na imanência da história conceitos e categorias essencialmente teológicas. Se se fala hoje tanto em pós-modenidade, é porque é essa modernidade teológica que entrou ema crise, na medida em que se desconfia do progresso, a tecnociência está enn crise, caiu o sonho do comunismo como soluçáo do enigma da história e náo se confia muito em utopias...

Já mais perto de nús, Francis Fukuyama também falou do wîm da história», na medida em que, com a queda do muro de Berlim, já naxda haveria de novo, pois o fururo caminharia, no domínio político, pela democracia e, no económico, pelo liberalismo: depois do fim da Uniáo Soviética e a libertação dos paises sacélices, por causa da falência do comunismo, a democracia liberal e a cconomia de mcrcado impor-se-iam por si ao mundo todo. Diga-se, de passagem, que esta tese já tinha sido avançada na Segunda Guerra Mundial por Alexindre Kojève. 
Embora no quadro do messianismo americano, era sobretudo a ideologia da história dos vencedores que estava em marcha. O próprio Fukuyama acabou já por recuar.. Afinal, a história, pela sua própria definição, é aberta... Náo é por acaso que, em 2008, outro politólogo americano, Robert Kagan, escreveu também um livro, mas com o título: $O$ regresso da História e o fim dos sonhos.

Depois, nesta visão, falta sempre a história dos vencidos - a história no seu reverso (Gustavo Gutiérrez). Há um provérbio africano, admirável neste domínio: um ditado sobre a memória mutilada. Diz assim: «Enquanto os leóes não tiverem os seus próprios historiadores, as histórias de caça continuaráo a glorificar o caçador».

À maneira de excursus, permitam uma palavra teológica. Há a historicidade, a história vivida, a história escrita, a filosofia da história. Mas a filosofia da história enquanto termo e consumaçáo (Ende e Vollendung) não é possível. Mas é pensável uma teologia da história. No quadro do entrecruzamento dos tempos, é pensável Deus como o Futuro absoluto, isto é, o Futuro de todos os passados, presentes e futuros. Deus enquanto Futuro absoluto consuma a história ao mesmo tempo que a abre ao sempre novo.

Aqui, ganha mais sentido a palavra enigmática de Heraclito, que Ernst Bloch resumiu deste modo: "Wer das Unverhoffte nicht erhofft wird es nicht finden" (quem náo espera o inesperado náo o encontrará). É também precisamente com ela que Fernando Catroga fecha a sua obra, à qual só posso desejar que tenha o êxito que uma obra de mestre merece.

Anselmo Borges Faculdade de Letras da Universidade de Coimbra
KOVÁCS, András Bálint - Screening Modernism. European Art Cinema, 19501980. Chicago: The University of Chicago Press, 2007. 432 p. (Cinema and Modernity Series) ISBN 978-0226451657.

András Bálint Kovács é professor do Institure for Art Theory and Media Research da ELTE University de Budapeste, director do National Audiovisual Archive de Budapeste e investigador de cinema que se dedica há mais de duas décadas ao estudo do cinema moderno na Europa das décadas de 196070.

Kovács tem publicado diversos trabalhos sobre história e estética do cinema: Les Mondes d'Andrej Tarkovsky (Lausanne, 1987); Metropolis, Paris: On German expressionism and the French New Wave (Budapeste, 1992); Tarkovszkij (Budapeste, 1997); Film and Narration (Budapeste, 1997); Collection of Essays (Budapeste 2002); Trends in Modern Cinema (Budapeste 2005).

Em Janeiro de 2008, a The University of Chicago Press deu à estampa o seu mais importante e reconhecido trabalho: Screening Modemism. European Art Cinema, 1950-1980 é o resultado de pesquisas e reflexóes contínuas desenvolvidas pelo autor desde 1998. A principal proposta desta obra é analisar exaustivamente, histórica e esteticamente, o cinema de arte (art cinema) que foi produzido em vários países europeus desde meados da década de 50 até meados dos anos 70 do século XX. Náo se trata, portanto, de uma história geral do cinema europeu desse período porque o autor defende que as obras filmicas que podem ser classificadas como art cinema constituem apenas uma excepçáo à produçáo cinematográfica europeia do mesmo período.

Em última análise, Kovács procura compreender a formaçáo do cinema moderno através da emergência da noçáo de cinema de autor (cinema of auteurship, do termo 